\title{
In Ovo Besleme
}

\section{Abbas Fadhıl Abdulqader Abdulqader, Osman Olgun*, Alp Önder Yıldız}

\author{
Selçuk Üniversitesi, Ziraat Fakültesi, Zootekni Bölümü, 42130 Selçuklu/Konya, Türkiye \\ *İletişim (correspondence): e-posta: oolgun@ @elcuk.edu.tr, Tel: +90 (332) 22328 09; Faks: +90 (332) 2410108 \\ Gönderim tarihi (Received): 20 Eylül 2017; Kabul tarihi (Accepted): 26 Kasım 2017
}

\section{$\ddot{O} z$}

Kuluçkadan çıkan civcivler aşılama, cinsiyet ayrımı ve yetiştirme kümeslerine nakillerinden dolayı 2-3 gün yem ve su tüketemeyebilirler. Civcivler aç kaldıkları dönemde sadece yumurta sarısındaki besin maddelerini kullanırlar. Bu durum, civcivlerin ileriki dönemlerdeki performansını olumsuz etkiler ve yetiştiricinin kârının azaltabilir. Bu olumsuz etki erken yemleme ile önlenebilir. Civcivler kuluçka sonrası mümkün olan en kısa zamanda yem ve su tüketmelidirler. Böylece çıkış sonrası performansları iyileşebilir. Amino asit, karbonhidrat, mineral ve vitamin gibi besin maddeleri embriyo besleme tekniği olan in ovo enjeksiyon ile civcivlere verilebilir. Kuluçka esnasında besin ve katkı maddelerinin enjeksiyonu kuluçkadan çıkış öncesi ve sonrası bağışıklı̆̆ı, kas ve sindirim sisteminin gelişimi etkiler. Sonuç olarak in ovo tekniğinin kullanımı başta etlik piliç yetiştiriciliği olmak üzere kanatlı sektöründe önemli rol üstenerek üreticinin karlılığını arttırabilecek bir yöntem olabilir.

Anahtar kelimeler: In Ovo, Aminoasit, Karbonhidrat, Vitamin, Mineral

\section{In Ovo Feeding}

\begin{abstract}
Chickens after the incubation cannot consume food and water for 2-3 days because of post-incubation vaccination, sex determination and transfer to breeding coops. The chickens use only nutrients in the egg yolk in the period they are hungry. In the case the performance of chickens will be adversely affected in future period and the profitability may decrease of producers. The adverse effect can be avoided by early feeding. Chickens should consume feed and water shortly after hatching. The nutrients such as amino acids, carbohydrate, mineral and vitamin can be given to the chickens by in ovo injection, which is the embryo feeding technique. Therefore, the performance of chickens after hatching can be improved. Injection of nutrients and additives during incubation affects immunity, the development of muscle and digestive system before and after incubation. Consequently, the use of in ovo technology can be a way to increase profitability poultry, especially in broiler breeding.
\end{abstract}

Keywords: In ovo, amino acid, carbohydrate, vitamin, mineral

\section{Giriş}

Kanatlı yetiştiriciliğinde civcivlerin çıkış sonrasında mümkün olan en k1sa zamanda sindirebilirliği yüksek, dengeli bir rasyon tüketmeleri ileri dönemlerdeki performanslarını önemli derecede etkilemektedir. Civcivin gelişimini ve sağlığını önemli oranda etkileyen unsurların başında yeme geçiş süreci ve başlatma döneminde tüketilen yemin kalitesi gelmektedir. $\mathrm{Bu}$ noktada civcivin yeterli ve gerekli besin rezervleri olacak şekilde hayata başlaması önem arz etmektedir. Çünkü yumurtalar yapılarının gereği dış çevreden ilave besin maddesi alamamaktadırlar. $\mathrm{Bu}$ nedenlerle embriyonun gelişmesi için gerekli olan enerji ve protein gibi besin maddelerinin yumurta oluşum aşmasında yumurtaya geçmesi ve birikmesi gerekmektedir (Palmer ve Guilette, 1991; Richards, 1997; Vieira, 2007).

Son y1llarda erken besleme yöntemlerinden olan in ovo besleme tekniği üzerine yapılan çalışmaların sayısında önemli bir artış söz konusudur. In ovo enjeksiyon yöntemi ile kuluçka döneminin herhangi bir zamanında yumurtaya besin maddeleri, aşı ve bazı uyarıcılar enjeksiyon edilmektedir. In ovo besleme tekniği Uni ve Ferket (2003) tarafından geliştirilmiş ve patent alınmıştır. In ovo besleme ile hastalık kontrolünün ve manejman uygulamalarının kolaylaştığı ve iş gücünden tasarruf sağlandığı bildirilmiştir (Sharma ve Burmester, 1984; Johnston ve ark., 1997). In ovo tekniği ilk olarak 1970'li yılların sonunda kullanılmaya başlamış ve 1995 yılında da otomatik enjeksiyon sistemleri (in ovoject) kullanılmaya başlamıştır (Johnston ve ark., 1997). Özellikle son on yıl içerisinde bu konu üzerine bilimsel araştırmaların sayısında önemli bir artış gözlenmektedir. $\mathrm{Bu}$ derlemede in ovo tekniği hakkında kısaca bilgi verilip, in ovo besleme üzerine yapılmış çalışmalar özetlenecektir. 


\section{In Ovo Enjeksiyon Bölgeleri ve Zamanı}

Kuluçkanın geç döneminde özellikle aşı uygulamaları için kullanılmakta olan in ovo tekniği, albümin (Beck ve ark., 2015), amniyotik sivi/kese (Uni ve Ferket, 2004), yumurta sarıs1 (Goel ve ark., 2013a) ve hava boşluğu (Kop Bozbay ve ark., 2016) gibi bölgelere uygulanmaktadır. Genellikle hava boşluğuna enjeksiyon yapılmasına rağmen uygun enjeksiyon yeri üzerine farklı önerilerde bulunulmaktadır. Bazı çalışmalarda sarı kesesinin en uygun enjeksiyon yeri olduğu (Ohta ve Kidd, 2001), bazı çalışmalarda ise en uygun enjeksiyon bölgesinin amniyotik sıvı olduğu bildirilmektedir (Uni ve Ferket, 2004). Ebrahimi ve ark. (2012) in ovo enjeksiyon bölgesi olarak kuluçka öncesi ve embriyonik gelişimin başlangıcında amniyotik kesenin, embriyonik gelişmenin daha sonraki aşamalarında ise genellikle sarı kesesinin daha uygun olacağını belirtmişlerdir. Sarı kesesi, yüzey alanı ve besin maddelerinin sindirilme derecesinin yüksek olması nedeniyle in ovo besleme için ideal bir durumdadır (Ebrahimi ve ark., 2012). Kuluçkanın 17. gününden sonra yumurta sarısının civciv tarafından abdomene çekilmesi başladığından dolayı in ovo enjeksiyon hava boşluğu ve amniyotik kese gibi yumurtanın farklı bir alanına uygulanabilir.

Yapılan çalışmalarda in ovo enjeksiyon kuluçka döneminin 0-7. günü (Al-Daraji ve ark., 2012; AlMurrani, 1982 ), 8-14. günü (Nowaczewski ve ark., 2012) ve 15-21. günü (Zhai ve ark., 2011a; Shafey ve ark., 2014) uygulanmıştır.

\section{In Ovo Besleme}

Son yıllarda çalışma sayısı artan in ovo besleme tekniği (yumurta içi besleme), kuluçkanın herhangi bir döneminde protein, vitamin ve mineral gibi besin maddelerinin ve hormon, antikor gibi çeşitli maddelerin embriyonik keselere sivi solüsyon formunda enjeksiyonu ile uygulanan bir yöntemdir (Herfiana, 2007). In ovo beslemenin iskelet (Hargis ve ark., 1989) ve bağışıklık sisteminin gelişimi (Goel ve ark., 2013a; Kadam ve ark., 2008; Salary ve ark., 2014), civcivlerin çıkış öncesi aşılanması, sindirim kapasitesinin artırılması ve bağırsak gelişiminin sağlanması (Uni ve Ferket, 2003), çıkış gücünün artırılması (Tako ve ark., 2004), ilk hafta ölümlerin azaltılması (Uni ve Ferket, 2004), kas gelişiminin artırılması ve çıkış sonrası canlı ağırlık ve yemden yararlanmanın iyileştirilmesi (Ohta ve ark., 1999; Bhanja ve ark., 2004) gibi yararlarının olduğu belirtilmektedir.

\section{In Ovo Amino Asit Beslemesi}

Bir embriyonun büyümesi ve gelişimi için bütün amino asitler gerekli olup, yumurtanın amino asit kompozisyonu yıllar içinde değişmemesine rağmen genetik seleksiyonun bir sonucu olarak embriyonun gelişimi için gerekli amino asit ihtiyaçları artmıştır (Kunachowicz ve ark., 1998; Okruszek and Wereńska, 2011). Ohta ve ark. (2001) embriyonik gelişim için tüm amino asitlerin gerekli olduğunu ve herhangi bir amino asidin yetersizliğinde protein sentezinde aksamalar olacağını, bunun sonucunda büyüme ve gelişmenin gerilemesine neden olacağını belirtmişlerdir. Damızlık tavukların rasyonlarını hazırlarken diğer besin maddelerinin yanı sıra ihtiyaç duyulan amino asitlerin sağlaması civciv kalitesi için oldukça önemlidir. Keshavarz ve Jackson (1992) protein ve amino asitler bakımından yetersiz rasyonlarla beslenen damızlık yumurtacı tavuklardan daha küçük yumurta elde edildiğini göstermişlerdir. Dolayısıyla kuluçka döneminde damızlık yumurtalarda amino asitlerin yeterince depolanmamasına bağlı olarak kuluçka döneminde ve kuluçka sonrası dönemde gelişim yetersizliğinin önlenmesi amacı ile in ovo amino asit beslemesi uygulanabilir.

Kadam ve ark. (2008) etlik damızlık yumurtalarına in ovo tekniğiyle 10, 20, 30 ve $40 \mathrm{mg}$ düzeylerinde treonin enjeksiyonu uygulamışlardır. Çalışma sonucunda $30 \mathrm{mg}$ treonin enjeksiyonu ile çıkış (\% 1-6) ve çıkış sonrası 4. hafta performans parametrelerinin kontrol grubuna göre daha iyi olduğunu, ancak muamelelerin sindirim enzimlerine etkisinin olmadığını bildirmişlerdir. Aynı yazarların başka bir çalışmasında yumurta sarısı içine treonin enjeksiyonunun yumurta albüminine enjeksiyonuna göre canlı ağırlığın \% 2.4 daha yüksek olduğu belirtilmiştir (Kadam ve ark., 2009).

Coşkun ve ark. (2014a) etlik damızlık yumurtalarında amniyotik sıviya DL-metiyonin takviyesinin canlı ağırlığı olumlu yönde etkilediğini bildirmişlerdir. Japon bıldırcınlarına kuluçkanın 0. gününde in ovo enjeksiyon ile $\% 0,1,2$ ve 3 seviyelerinde L-arjinin uygulanan başka bir çalışmada kuluçka randımanı, çıkış ağırlığı ve yem tüketiminin etkilenmediği, çıkış sonrası canlı ağırlık ve yemden yararlanma oranı ile serum glukoz, protein, toplam protein, kalsiyum ve fosfor konsantrasyonlarının önemli oranlarda arttığı, bunun yanı sıra karkas, göğüs, but, karaciğer, kalp ve taşlık ağırlıklarının L-arjinin seviyesine bağlı olarak arttığı, abdominal yağ oranının ise azaldığı bildirilmiştir (AlDaraji ve ark., 2012). Saki ve ark. (2013) etlik damızlık 
yumurtalarına kuluçkanın 5. günü $20 \mathrm{mg} / \mathrm{ml}$ seviyesinde arjinin ilavesi ile yem tüketiminin arttığını ve yemden yararlanma oranının iyileştiğini bildirmişlerdir. Shafey ve ark. (2014) ise kuluçkanın 18. gününde arjinin ve lisinin yumurtaya enjeksiyonu ile 42. gün canlı ağırlığın daha yüksek olduğunu ve arjinin enjeksiyon yapılan yumurtalardan daha erken çıkış olduğunu bildirmişlerdir. Foye ve ark. (2007) hindilerde in ovo arjinin beslemenin pankreas enzimlerinin aktivitesini arttırdığını, büyüme hormonu salgısını uyardığını dolayısıyla embriyonun gelişimini olumlu etkilediğini belirtmişlerdir. Hazim ve ark. (2011) damızlık bıldırcın yumurtalarına arjinin in ovo enjeksiyonunun çıkış randımanını, çıkış sonrası canlı ağırlığı, canlı ağırlık artışını ve yemden yararlanmayı olumlu yönde etkilediğini bildirmişlerdir.

In ovo tekniği ile yumurtaya bireysel amino asit verilmesinin yanı sıra bazı çalışmalarda amino asitler karışım olarak verilmiştir. Al-Murrani (1982) yumurtanın amino asit bileşimi ile benzer oranda amino asit karışımının kuluçkanın 7. gününde yumurtaya enjeksiyonu ile hem civcivlerin çıkış ağırlığının ve hem de 56. gün canlı ağırlığının olumlu yönde etkilendiğini bildirmiştir. Ohta ve ark. (1999) damızlık yumurtaların glisin ve prolin gibi amino asit konsantrasyonunun kuluçka döneminin son aşamasında embriyonik gelişimi desteklemek için yeterli olmayabileceğini bildirmişlerdir. Benzer şekilde Bhanja ve Mandal (2005) glisin ve prolin in ovo enjeksiyonu uygulamasının, kontrol grubu ve izolösin, lösin ve valin in ovo uygulamasına göre civciv çıkış ağırlığı ve ileri yaşlardaki canlı ağırlıklarının daha yüksek olduğunu bildirmişlerdir.

\section{In Ovo Karbonhidrat Beslemesi}

Bir embriyonun büyümesi yüksek enerji talebi ile ilişkilidir. Tavuk yumurtaları protein ve yağ bakımından zengindir, ancak karbonhidrat içeriği oldukça düşüktür (Burley ve Vadehra, 1989). Glukoz embriyoda esas olarak karaciğerde ve kaslarda glikojen şeklinde depolanır. Yumurtanın karbonhidrat içeriği embriyonun metabolik ve fizyolojik ihtiyaçlarını karşılamada yetersiz olduğu için glukoz ihtiyacı lipoliz ve proteolizden elde edilen glikojenik maddeler olan gliserol veya glikonejik amino asitlerden karşılanmaya çalışılır (Klasing, 1998). Dolayısıyla embriyonik gelişim sırasında başta glukoz olmak üzere karbonhidrat kaynağı verilmesinin civciv kalitesini ve performansını olumlu yönde etkilemesi beklenir.

Bhanja ve ark. (2008) tarafindan etlik damızlıklarda yapılan bir çalışmada kuluçkanın 18. gününde $50 \mathrm{mg}$ glukoz in ovo enjeksiyonunun çıkış ağırlığına etkisinin olmadığını, ancak plazma glukoz ve protein seviyesinin ve karaciğer, bezel mide ve taşlık ağırlıklarının kontrol grubuna göre daha yüksek olduğunu, çıkış sonrası 10 . gün plazma glukoz ve ürik asit miktarının ise düştügüüü ve ince bağırsak ağırlığının arttığını bildirmişlerdir. Zhai ve ark. (2011b) etlik damızlık yumurtalarına kuluçkanın 18.5 günü $0.1,0.4,0.7$ ve $1.0 \mathrm{ml}(0.25 \mathrm{~g} / \mathrm{ml})$ seviyelerinde glukoz, fruktoz, sukroz, maltoz ve dekstrin enjeksiyonu ile civcivlerin çıkış ağırlığının ve sarı kesesi ağırlığının arttığını, ancak çıkış oranının ve karaciğer ağırlığının düştüğünü belirtmişlerdir. Aynı araştırıcılar başka bir çalışmada in ovo beslemede karbonhidrat kaynağı olarak fruktoz kullanılmasının uygun olmadığını belirtmişlerdir (Zhai ve ark., 2011a). Embriyonik gelişim sırasında karbonhidrat enjeksiyonu ile civcivlerin vücut ağırlığında gözlemlenen artış, günlük yaştaki civcivlerin gastrointestinal sisteminin gelişimiyle ilişkili olabilir. Kornasio ve ark. (2011) etlik damızlık yumurtalarına dekstrin ve $\beta$-hidroksi- $\beta$-bütirik asit in ovo enjeksiyonunun çıkış sonrası karaciğer ve kaslarda glikojen miktarının ve uydu hücrelerini uyararak kas gelişiminin dolayısıyla canlı ağırlık artışının yüksek olmasına neden olduğunu belirtmişlerdir. Salmanzadeh ve ark. (2012) yaptıkları çalışmada damızlık tavuk yumurtalarına glukoz ve magnezyum enjeksiyonunun çıkış ve deneme sonu canlı ağırlığını, karkas randımanını, göğüs eti miktarını, 21. gün plazma glukoz ve magnezyum seviyesini arttırdığını ve yemden yararlanmayı olumlu etkilediğini, ancak kuluçka randımanını düşürdüğünü bildirmişlerdir. Kuluçkanın 22. gününde damızlık hindi yumurtalarına laktoz in ovo enjeksiyonunun hindi palazlarında bağırsak villus uzunluğunu olumlu etkilediği saptanmıştır (Bohórquez ve ark., 2007). Damızlık ördek yumurtalarına in ovo glutamin, sukroz ve maltoz karışımı enjeksiyonunun kuluçkanın 25. günü ve deneme sonu canlı ağırlığı ve göğüs eti oranının artmasına neden olduğu ve bağırsak gelişimini olumlu etkilediği bildirilmiştir (Chen ve ark., 2009).

\section{In Ovo Vitamin Beslemesi}

Vitaminler embriyo gelişimi esnasında birçok fizyolojik ve metabolik olaylarda, bağışıklık sisteminde rol alırlar. Böylece çıkış oranı, civciv kalitesi ve çıkış sonrası performansın artmasını sağlarlar. Goel ve ark. (2013a) yaptıkları bir çalışmada kuluçkanın 14. gününde yumurtaya A (105 IU), B 1 (18 $\mu \mathrm{g}), \mathrm{B}_{2}(36 \mu \mathrm{g}), \mathrm{B}_{6}(35 \mu \mathrm{g})$ ve $\mathrm{E}$ (1.4 IU) vitaminlerini in ovo enjeksiyon yöntemi ile vermişlerdir. Deneme sonucunda çıkış ağırlığının $B_{6}$ 
vitamini enjeksiyonu ile düştüğü, ancak deneme sonu canlı ağırlığa etkisinin olmadığı, $A, B_{1}, B_{2}$ ve $E$ vitaminlerinin uygulandığı gruplarda dişilerin 14. gün canlı ağırlığının daha yüksek olduğu, in ovo vitamin enjeksiyonunun deneme sonu (42. gün) canlı ağırlık artışını olumlu etkilediği belirtilmiştir. Başka bir çalışmada ise etlik damızlık yumurtalarına $B_{6}$ vitamini $(100 \mu \mathrm{g})$ enjeksiyonunun çıkış oranını arttırdığı, $\mathrm{B}_{1}(100$ $\mu \mathrm{g})$ ve $\mathrm{E} \quad(0.5 \mathrm{UI})$ vitaminleri enjeksiyonunun çıkış oranını düşürdüğü ve 14. ve 28. günlük canlı ağırlığ1 arttırdığı, A (100 UI) ve C (50 mg) vitaminlerinin enjeksiyonunun ise çıkış ağırlığını arttırdığı bildirilmiştir (Bhanja ve ark., 2007). Ördek yumurtalarına kuluçkanın 12. gününde $\mathrm{E}(10 \mathrm{mg})$ ve $\mathrm{C}(3 \mathrm{mg})$ vitaminleri enjeksiyonunun muamele gruplarındaki hayvanların 42 . gün yemden yararlanma oranının olumsuz etkilenmesine rağmen canlı ağırlıklarının daha yüksek olduğu belirtilmiştir (Selim ve ark., 2012). Nowaczewski ve ark. (2012) etlik damızlık yumurtalarına kuluçkanın 13., 15. ve 17. günlerinde 3 ve $6 \mathrm{mg}$, ördek yumurtalarına kuluçkanın 12. ve 20. günlerinde 4 ve $8 \mathrm{mg} \mathrm{C}$ vitamini enjeksiyonunun etlik piliçlerde çıkış oranını etkilemediğini, ancak ördek yumurtalarında çıkış oranının vitamin $\mathrm{C}$ enjeksiyonu ile arttığını bildirmişlerdir. Etlik damızlık yumurtalarına kuluçka öncesi 100, 150 ve 200 IU seviyelerinde A vitamini enjeksiyonunun PCV (kan hücrelerinin hacminin oranı), WBC (beyaz kan hücre miktarı) ve lenfosit değerlerinin değiştirdiği, heterofil ve H/L oranını azalttığı, 100 IU A vitamin uygulanan gruplarda 21. ve 35. günlerde plazma toplam protein konsantrasyonunu arttırdığı ve ürik asit seviyesini ise düşürdüğü bildirilmiştir (Abdul-Lateif ve Al-Shamari., 2014). Salary ve ark. (2014) etlik damızlı yumurtalarına $30 \mathrm{mg}$ E vitamini enjeksiyonunun civcivlerin çıkış sonrası performansinı ve kan IgG, IgM ve $\operatorname{IgA}$ seviyelerini olumlu yönde etkileyerek piliçlerin bağışıklık sistemini desteklediğini bildirmişlerdir.

\section{In Ovo Mineral Beslemesi}

Mineraller canlılarda yapısal fonksiyonlarının yanı sıra birçok metabolik ve fizyolojik olaylara dahil olurlar. Beck ve ark. (2015) tavuk embriyoların üzerine yaptıkları bir çalışmada in ovo tekniğiyle nano gümüş, hidroksiprolin ve bunların karışımının enjeksiyonunun kuluçkanın 20. gününde embriyonal gelişimi etkilemediğini, kıkırdaklardaki kollejen gelişimin iyileştiğini ve damar boyutunu arttırdığını bildirmişlerdir. Etlik damızlık yumurtalarına kuluçkanın 5. günü nano gümüş (30 ve $45 \mathrm{mg}$ ), kekik (75 ve $100 \mathrm{mg}$ ) ve geyik otu (75 mg) ekstraktlarının in ovo tekniğiyle enjeksiyonunun çıkış oranını etkilememeksizin 14. ve 21. gün kemik mineralizasyon ve bağışıklığı geliştirdiği bildirilmiştir (Saki ve Salary, 2015). Nano gümüş in ovo enjeksiyonu ile ilgili yapılan başka bir çalışmada ise Goel ve ark. (2017) kuluçkanın 18. günü nano gümüş $(12.5,25$ ve 50 $\mu \mathrm{g})$ enjeksiyonunun kuluçka randımanını, çıkış sonrası büyüme dahil diğer performans parametrelerini etkilememeksizin çıkış sonrası bağışıklığı iyileştirdiğini belirtmişlerdir.

Etlik damılık yumurtalarına in ovo enjeksiyonla $0.5 \mathrm{ml}$ (\% 50 ve 100) kalsiyum, fosfor ve vitamin D karışımının kuluçkanın 1. gününde uygulanması sonucu çıkış sonrası 1. gün kemik külü, fosfor ve bakır seviyelerinin, 21. gün kemik kalsiyum ve fosfor seviyeleri ile yem tüketiminin arttığ Lee ve ark. (2014) yaptıkları bir çalışmada etlik damızlık yumurtalarına kuluçkanın 18. gün in ovo tekniğiyle 0,10 ve $20 \mu \mathrm{g}$ seviyelerinde selenyum enjeksiyonunun nekrotik enterit kaynaklı patojenlere maruz birakılan civcivlerde bağışıklık ve antioksidan kapasitelerinin arttırılması için yararlı olabileceğini bildirmişlerdir. Oliveira ve ark. (2015) etlik damızlık yumurtaları üzerine yaptıkları bir denemede kuluçkanın 17. gününde farklı seviyelerde organik çinko, manganez ve bakır karışımı (sirasiyla $0.181,0.087$ ve $0.010 \mathrm{mg} / \mathrm{mL}, 0.544,0.260$ ve $0.030 \mathrm{mg} / \mathrm{mL}$ ) in ovo enjeksiyonunun kuluçka ve kemik parametreleri üzerine etkisini araştırmıştır. Çalışmanın sonucunda yüksek seviyede mineral karışımı enjeksiyonunun çıkış gücünü negatif etkilemesine rağmen tibia mineralizasyonunu önemli derecede artırdığını ve diğer kemik özelliklerini ise etkilemediğini bildirmişlerdir.

Başka bir çalışmada ise nano çinko $(20,40,60$ ve $80 \mu \mathrm{g})$, bakır $(4,8,12$ ve $16 \mu \mathrm{g})$ ve selenyumun $(0.075,0.15$, 0.225 ve $0.30 \mu \mathrm{g})$ kuluçkanın 18. gününde in ovo tekniğiyle enjeksiyonu sonucunda çıkış oranının etkilenmemesine rağmen yem tüketiminin ve göğüs eti oranının olumlu yönde etkilendiği belirtilmiştir (Joshua ve ark., 2016). Goel ve ark. (2013b) kuluçkanın 14. gününde in ovo tekniği ile bakır $(8 \mu \mathrm{g})$ ve demir $(80 \mu \mathrm{g})$ enjeksiyonunun çıkış ağırlığı ve çıkış sonrası 14. gün canlı ağırlığını etkilemediği, 42. gün canlı ağırlığın, bağışıklığın, büyüme hormonu ve insülin benzeri büyüme faktörün-II (IGF-II)'nin pozitif etkilediğini bildirmişlerdir. Mroczek-Sosnowska ve ark. (2017) kuluçkanın 1. günü $0.3 \mathrm{ml}$ nano bakır $(50 \mathrm{mg} / \mathrm{kg}$ ) in ovo uygulamasının etlik piliçlerde femur ağırlığını ve kırılma direncini arttırdığı, dolayısıyla in ovo nano bakır ilavesinin etlik piliçlerdeki zayıf kemik sorununu azaltmak için alternatif bir faktör olabileceğini belirtmiştir. 


\section{Etken Maddelerin In Ovo Tekniği ile Verilmesi}

Katkı maddeleri hayvanın performansını ve/veya ürün kalitesini olumlu yönde etkileyen kendilerinin besleme değeri olmayan yararlı maddelerdir. In ovo tekniği üzerine yapılan araştırmaların artmasıyla birlikte yemlere ilave edilen katkı maddelerinin in ovo tekniğinde uyarlanması hız kazanmaktadır. $\mathrm{Bu}$ sayede çıkış sonrası performansın artması beklenmektedir.

Kop Bozbay ve ark. (2016) kuluçkanın 18. günü hava kesesine propolisin in ovo uygulandığı bir çalışma sonucunda, propolis enjeksiyonunun çıkış oranını arttırdığı, ancak çıkış ağırlığını düşürdüğünü bildirmişlerdir. Propolisin etkileri üzerine yapılan başka bir çalışmada ise bıldırcın yumurtalarına kuluçkanın 14 . gününde $0.20 \mathrm{ml}$ in ovo propolis (\% 1, 2 ve 3) uygulamasının sonucunda $\% 1$ propolis enjeksiyonunun incelenen parametrelere herhangi bir etkisinin olmadığı, ancak \% 2 ve 3 propolis uygulamasının embriyonik ölümleri ve kuluçka randımanını negatif etkilediği, diğer parametrelere ise negatif etkilerinin olmadığı bildirilmiştir (Aygun, 2016).

Maiorano ve ark. (2012) yaptıkları bir çalışmada, kuluçkanın 12. gününde prebiyotik (raffinoz) ve prebiyotik + probiyotik (raffinoz + Lactococcus lactis ssp. ve lactis $S L 1$, raffinoz + Lactococcus lactis ssp. ve cremoris IBB SCl ve laktoz + Lactococcus acidophilus, Streptococcus faecium) in ovo teknik ile etlik damızlık yumurtalarına enjeksiyon yapmışlardır. Çalışma sonucunda prebiyotik olarak laktoz + probiyotik enjeksiyonu karkas randımanını ve yemden yararlanma oranını olumsuz etkilediğini, kas lif kalınlığını ve yoğunluğunun kontrol grubuna göre daha düşük olduğunu bildirmişlerdir. Bir diğer çalışmada ise kuluçkanın 12. gününde hava boşluğuna ticari prebiyotik ve probiyotik preparatlarının in ovo enjeksiyonu sonucunda etlik piliçlerin 34. gün pankreas büyüklüğünün etkilenmemesine rağmen amilaz, lipaz ve tripsin salgılarının ve canlı ağırlığın arttığı bildirilmiştir (Pruszynska-Oszmalek ve ark., 2015)

Jafari Ahangari ve ark. (2013) yaptıkları bir denemede arı sütünün in ovo enjeksiyonu ile civcivlerde gelişimin ilk aşamalarında büyüme performansının ve yem tüketiminin olumlu etkilendiğini bildirmişlerdir. Hajati ve ark. (2014) kuluçkanın 18. gününde $4.5 \mathrm{mg}$ seviyesinde üzüm çekirdeği ekstraktının enjeksiyonunun çıkış oranını artırdığını, çıkış ağırlığını etkilemediğini, çıkış sonrası canlı ağırlık artışı ve yem tüketimini arttığını, ileum $E$. coli miktarını azalttığını bildirmiştir. Coşkun ve ark. (2014b) etlik damızlık yumurtalarına kuluçkanın 16. günü polen ekstrakı enjeksiyonunun civciv ağırlı̆̆ı oranını arttırdığını belirtmişlerdir.

\section{Sonuç}

In ovo besleme tekniği civcivlerin embriyonal dönemde bağırsak gelişimi ve bağışıklık sistemi gelişmiş ve civcivlerin daha fazla besin maddesi depolamış olarak yumurtadan çıkmasını sağlamaktadır. Böylece civcivlerin kalitesi, yaşama gücü ve ileriki yaşlardaki performansı iyileşebilmekte ve başta etlik piliç sektörü olmak üzere kanatlı sektöründe kârlılı̆̆ın arttırılması sağlanabilmektedir. Aynı zamanda besin maddelerinin embriyonal dönemde verilmesi özellikle damızlıkların beslenmesinde yapılabilecek hataların kuluçka randımanı ve civciv kalitesine muhtemel olumsuz etkilerinin önlenmesinde daha da önem kazanmaktadır.

$\mathrm{Bu}$ teknolojideki başlıca problemler ise enjeksiyon bölgesi ve enjeksiyon zamanı hakkında net bir bilginin olmayışı ve kuluçka randımanındaki düşüşlerdir. Son 10 yıl içerisinde in ovo enjeksiyon üzerine yoğun araştırmalar yapılması bu problemlerin azalmasını veya ortadan kalkmasını sağlayacaktır. Bununla birlikte kuluçkahanelerde aşı uygulaması için geliştirilen otomatik in ovo enjeksiyon sistemlerine besin ve katk1 maddelerinin de eklenmesi ile in ovo beslemenin sağlayacağı avantajları yaygınlaştıracaktır.

\section{Kaynaklar}

Abdul-Lateif M, Al-Shamari MA. 2014. The effect of in ovo injection with different concentration of vitamin A on some blood traits of broiler chicken. Iraqi Journal of Agricultural Science 45 (Spec. Iss): 376-383.

Al-Daraji HJ, Al-Mashadani AA, Al-Hayani WK, AlHassani AS, Mirza HA. 2012. Effect of in ovo injection with L-arginine on productive and physiological traits of Japanese quail. South African Journal of Animal Science 42:139-145.

Al-Murrani WK. 1982. Effect of injecting amino acids in to the egg on embryonic and subsequent growth in the domestic fowl. British Poultry Science 23:171-174.

Aygun A. 2016. The effects of in-ovo injection of propolis on egg hatchability and starter live performance of japanese quails. Brazilian Journal of Poultry Science 2(Spec Iss): 087-094.

Beck I, Hotowy A, Sawosz E, Grodzik M, Wierzbicki M, Kutwin M, Jaworski S, Chwalibog A. 2015. Effect of 
silver nanoparticles and hydroxyproline, administered in ovo, on the development of blood vessels and cartilage collagen structure in chicken embryos. Archive Animal Nutrition 69: 57-68.

Bhanja SK, Mandal AB, Goswami TK. 2004. Effect of in ovo injection of amino acids on growth, immune response, development of digestive organs and carcass yields of broilers. Indian Jounal of Poultry Science 39: 212-218

Bhanja SK, Mandal AB. 2005. Effect of in ovo injection of critical amino acids on pre- and post-hatch growth, immunocompetence and development of digestive organs in broiler chickens. AsianAustralasian Journal of Animal Sciences 18: 524531.

Bhanja SK, Mandal AB, Agarwal SK, Majumdar S, Bhattacharyya A. 2007. Effect of in ovo injection of vitamins on the chick weight and post-hatch growth performance in broiler chickens. Proc. XVI European Symposium on Poultry Nutrition, Strasbourg, France, 26 - 30.08.2007.

Bhanja SK, Mandal AB, Agarwal SK, Majumdar S 2008. Effect of in ovo glucose injection on the post hatch-growth, digestive organ development and blood biochemical profiles in broiler chickens. Indian Journal of Animal Science 78:869-872.

Bohórquez D, Santos Jr A, Ferket P. 2007. In ovo-fed lactose augments small intestinal surface and body weight of 3 day-old turkey poults. Poultry Science $86: 214-215$.

Burley RW, Vadehra DV. 1989. The avian egg chemistry and biology. New York, USA, John Wiley and Sons.

Chen W, Wang R, Wan HF, Xiong XL, Peng P, Peng J. 2009. Infulence of in ovo injection of glutamine and carbohydrates on digestive organs and pectoralis muscle mass in the duck. British Poultry Science $50: 436-442$

Coşkun İ, Erener G, Şahin A, Karadavut U, Altop A, Okur AA. 2014a. Impacts of in ovo feeding of DLmethionine on hatchability and chick weight. Turkish Journal of Agriculture - Food Science and Technology 2:47-50.

Coşkun İ, Çayan H, Yılmaz Ö, Taşkın A, Tahtabiçen E, Şamlı HE. 2014b. Effects of in ovo pollen extract injection to fertile broiler eggs on hatchability and subsequent chick weight. Turkish Journal of Agricultural and Natural Sciences 1: 485-489.
Ebrahimi MR, Jafari Ahangari Y, Zamiri MJ, Akhlaghi A, Atashi H. 2012. Does pre-incubational in ovo injection of buffers or antioxidants improve the quality and hatchability in long-term stored eggs? Poultry Science 91:2970-2976.

Foye OT, Ferket Uni Z. 2007. The effects of in ovo feeding arginine, $\beta$-hydroxy- $\beta$ - methyl-butyrate, and protein on jejunal digestive and absorptive activity in embryonic and neonatal turkey poults. Poultry Science 86:2343-2349.

Ghobadi N and Hemati Matin HR. 2015. Response of broiler chicks to in ovo injection of calcium, phosphorus, and vitamin d complex (cadphos). Global Journal of Animal Scientific Research 3: 544-549.

Goel A, Bhanja SK, Panda V, Mehra M, Mandal A. 2013a. Effects of in ovo administration of vitamins on post hatch-growth, immunocompetence and blood biochemical profiles of broiler chickens. Indian Journal of Animal Science 83:916-921.

Goel A, Bhanja SK, Mehra M, Majumdar S, Panda V. 2013b. Effect of in ovo copper and iron feeding in broiler chicken Indian Journal of Animal Science 48: 279-285.

Goel A, Bhanja SK, Mehra M, Majumdar S, Mandal A. 2017. In ovo silver nanoparticle supplementation for improving the post-hatch immunity status of broiler chickens. Archive Animal Nutrition 71: 384-394.

Hajati H, Hassanabadi A, Golian A, NassiriMoghaddam H, Nassiri MR. 2014. The effect of in ovo injection of grape seed extract and vitamin $\mathrm{C}$ on hatchability, antioxidant activity, yolk sac absorption, performance and ileal micro flora of broiler chickens. Research Opinions in Animal and Veterinary Sciences 4: 633-638.

Hargis PS, Pardue SL, Lee AM, Sandel GW. 1989. In ovo growth hormone alters growth and adipose tissue development of chickens. Growth, Development, and Aging 53: 93-99.

Hazim J, Al-Daraji AA, Al-Mashadani WK, Al-Hayani AS, Al-Hassani Mirza HA. 2011. Influence of in ovo injection of L-arginine on productive and physiological performance of quail. Research Opinions in Animal and Veterinary Sciences 1: 463467.

Herfiana IM. 2007. The effect of glutamine, dextrin and its combination through in ovo feeding on immune response, blood profiles and the carcass composition 
of male broiler chicken. Msc thesis. Sekolah Pascasarjana, Institute pertanin, Bogor.

Jafari Ahangari Y, Hashemi SR, Akhlaghi A, Atashi H, Esmaili Z, Ghorbani M, Mastani R, Azadegan A, Davoodi H. 2013. Effect of in ovo injection of royal jelly on post hatch growth performance and immune response in broiler chickens challenged with newcastle disease virus. Iranian Journal of Applied Animal Science 3:201-206.

Johnston PA, Liu H, O’Connell T, Phelps P, Bland M, Tyczkowski J, Kemper A, Harding T, Avakian A, Haddad E, Whitfill C, Gildersleeve R, Ricks CA. 1997. Applications in in ovo technology. Poultry Science 76:165-178.

Joshua PP, Valli C, Balakrishnan V. 2016. Effect of in ovo supplementation of nano forms of zinc, copper, and selenium on post-hatch performance of broiler chicken. Veterinary World 9: 287-294.

Kadam MM, Bhanja SK, Mandal AB, Thakur R, Vasan P, Bhattacharyya A, Tyagi JS. 2008. Effect of in ovo threonine supplementation on early growth, immunological responses and digestive enzyme activities in broiler chickens. British Poultry Science 49:736-741.

Kadam MM, Bhanja SK, Mandal AB, Tyagi PK, Patil AR. 2009. Influence of in ovo threonine injection site on early post-hatch growth and digestive organ development of broiler chicken. Journal of Animal Physiology and Animal Nutrition 44:203-205.

Keshavarz K, Jackson ME. 1992. Performance of growing pullets and laying hens fed low-protein amino acid supplemented diets. Poultry Science 71:905-918.

Klasing KC. 1998. Carbohydrates in comparative avian nutrition. New York, USA, CAB Int, 201-209.

Kop Bozbay C, Konanç K, Ocak N, Öztürk E. 2016. The effects of in ovo injection of propolis and injection site on hatchability, hatching weight and survival of chicks. Türkiye Tarımsal Araştırmalar Dergisi 3: 48-54.

Kornasio R, Halevy O, Kedar O, Uni Z. 2011. Effect of in ovo feeding and its interaction with timing of first feed on glycogen reserves, muscle growth, and body weight. Poultry Science 90:1467-1477.

Kunachowicz H, Nadolna I, Przygoda B, Iwanow K. 1998. Tables of nutritional values of food products (in Polish). Warszawa, Poland.

Lee SH, Lillehoj HS, Jang SI, Jeong MZ, Xu SS, Kim
JB, Park HJ, Kim HR, Lillehoj EP, Bravo D. 2014. Effects of in ovo injection with selenium on immune and antioxidant responses during experimental necrotic enteritis in broiler chickens. Poultry Science 93:1113-1121.

Maiorano G, Sobolewska A, Cianciullo D, Walasik K, Elminowska-Wenda G, Sławińska A, Tavaniello S, Żylińska J, Bardowski J, Bednarczyk M. 2012. Influence of in ovo prebiotic and symbiotic administration on meat quality of broiler chickens. Poultry Science 91:2963-2969.

Mroczek-Sosnowska N, Łukasiewicz M, Adamek D, Kamaszewski M, Niemiec J, Wnuk-Gnich A, Scott A, Chwalibog A, Sawosz E. 2017. Effect of copper nanoparticles administered in ovo on the activity of proliferating cells and on the resistance of femoral bones in broiler chickens. Archive Animal Nutrition 71:327-332.

Nowaczewski S, Kontecka H, Krystianiak S. 2012. Effect of in ovo injection of vitamin $\mathrm{C}$ during incubation on hatchability of chickens and ducks. Folia Biology 60:93-97.

Ohta Y, Tsushiman N, Koide K, Kidd MT, Ishibashi T. 1999. Effect of amino acid injection in broiler breeder eggs on embryonic growth and hatchability of chicks. Poultry Science 78:1493-1498.

Ohta Y, Kidd MT. 2001. Optimum site for in ovo amino acid injection in broiler breeder eggs. Poultry Science 80: 1425-1429.

Ohta Y, Kidd MT, Ishibashi T. 2001. Embryo growth and amino acid concentration profiles of broiler breeder eggs, embryos, and chicks after in ovo administration of amino acids. Poultry Science 80:1430-1436.

Okruszek A, Wereńska M. 2011. Wartość odżywcza rożnego rodzaju jaj. NIT, 3: 212-224.

Oliveira TFB, Bertechini AG, Bricka RM, Kim EJ, Gerard PD, Peebles E.D. 2015. Effects of in ovo injection of organic zinc, manganese, and copper on the hatchability and bone parameters of broiler hatchlings. Poultry Science 94:2488-2494.

Palmer BD, Guilette Jr LJ. 1991. Oviductal proteins and their influence on embryonic development in birds and reptiles. Egg incubation its effects (Ed: D. Charles Deeming, Mark W. J. Ferguson) Cambridge University Press., New York, pp. 29-46.

Pruszynska-Oszmalek E, Kolodziejski PA, Stadnicka K, Sassek M, Chalupka D, Kuston B, Nogowski L, 
Mackowiak P, Maiorano G, Jankowski J, Bednarczyk M. 2015. In ovo injection of prebiotics and synbiotics affects the digestive potency of the pancreas in growing chickens. Poultry Science 94:1909-1916.

Richards MP. 1997. Trace mineral metabolism in the avian embryo. Poultry Science 76:152-164.

Saki A, Haghighat M, Khajali F. 2013. Supplemental arginine administered in ovo or in the feed reduces the susceptibility of broilers to pulmonary hypertension syndrome. British Poultry Science 54:575-580.

Saki AA, Salary J. 2015. The impact of in ovo injection of silver nanoparticles, thyme and savory extracts in broiler breeder eggs on growth performance, lymphoid-organ weights, and blood and immune parameters of broiler chicks. Poultry Science Journal 3:165-172.

Salary J, Sahebi-Ala F, Kalantar M, Reza H, Matin H. 2014. In ovo injection of vitamin $\mathrm{E}$ on post-hatch immunological parameters and broiler chicken performance. Asian Pacific Journal of Tropical Biomedicine 4:616-619.

Salmanzadeh M, Ebrahimnezhad Y, Aghdam Shahryar H, Beheshti R. 2012. The effects of in ovo injection of glucose and magnesium in broiler breeder eggs on hatching traits, performance, carcass characteristics and blood parameters of broiler chickens. Archive Animal Breeding 76:277-284.

Selim Sh A, Gaafar KM, El-Ballal SS. 2012. Influence of in ovo administration with vitamin $\mathrm{E}$ and ascorbic acid on the performance of Muscovy ducks. Emirates Journal of Food and Agriculture 24:264271.
Shafey TM, Mahmoud AH, Alsobayel AA, Abouheif MA. 2014. Effects of in ovo administration of amino acids on hatchability and performance of meat chickens. South African Journal of Animal Science 44:123-130.

Sharma JM, Burmester BR. 1984. Disease control in avian species by embryonal vaccination. U.S. Patent No. $4,458,630$.

Tako E, Ferket PR, Uni Z. 2004. Effects of in ovo feding of carbohydrates and beta-hydroxybetamethylbutyrate on the development of chicken intestine. Poultry Science 83:2023-2028.

Uni Z, Ferket PR. 2003. Enhancement of development of oviparious species by in ovo feding. US Patent $6,592,878$. North Carolina State University, Raleigh, NC; and Yissum Research Development Company of the Hebrew University of Jerusalem, Jerusalem (Israel).

Uni Z, Ferket PR. 2004. Methods for early nutrition and their potential, World's Poultry Science Jounal 60:101-111.

Vieira SL. 2007. Chicken embryo utilization of egg micronutrients. Brazilian Journal of Poultry Science 9:1-8.

Zhai W, Gerard PD, Pulikanti R, Peebles ED. 2011a. Effects of in ovo injection of carbohydrates on embryonic metabolism, hatchability, and subsequent somatic characteristics of broiler hatchlings. Poultry Science 90:2134-2143.

Zhai W, Rowe DE, Peebles ED. 2011b. Effects of commercial in ovo injection of carbohydrates on broiler embryogenesis. Poultry Science 90:12951301. 